\title{
Recovery of the failing heart: emerging approaches and mechanisms in excitation-contraction coupling
}

\author{
Michael Ibrahim, Joy C. E. Edlin, Anas Nader and Cesare M. N. Terracciano*
}

Address: National Heart and Lung Institute, Imperial College London, Imperial College Road, South Kensington, London, SW7 2AZ, UK

*Corresponding author: Cesare MN Terracciano (c.terracciano@imperial.ac.uk)

Fl000Prime Reports 2014, 6:27 (doi:10.12703/P6-27)

All Fl000Prime Reports articles are distributed under the terms of the Creative Commons Attribution-Non Commercial License (http://creativecommons.org/licenses/by-nc/3.0/legalcode), which permits non-commercial use, distribution, and reproduction in any medium, provided the original work is properly cited.

The electronic version of this article is the complete one and can be found at: http://f1000.com/prime/reports/m/6/27

\begin{abstract}
Heart failure (HF) is a growing cause of morbidity and mortality globally. All clinical therapies that reduce mortality have been shown to induce reverse remodeling. In this article, we discuss a conceptual approach to the evolving treatment of HF using emerging treatment modalities for the drug-refractory patient. This approach is based on the combinatorial, integrated application of therapies shown to influence reverse remodeling in the laboratory.
\end{abstract}

\section{Introduction}

The mechanisms underlying HF remain largely undetermined. Our understanding of the pathogenesis of HF has evolved into its current form: a series of complex interacting biological events leading to the clinical syndrome of HF, so-called cardiac remodeling [1]. The therapeutic approach to the failing heart has changed dramatically alongside our understanding of its pathophysiology. In 50 years, treatment has changed from positive inotropes to negative inotropes, from rest to exercise training [2] and from vasodilators to angiotensinconverting enzyme inhibitors (ACEis). Today, the mainstay of therapy is ACEi, diuretics, and $\beta$-adrenergic blockers. It is also notable that, to date, all the therapies that enhance survival have an effect on correcting the fundamental remodeling identified in basic science studies [3]. This concept has culminated in reversal of clinical HF in selected patients. Laboratory work has begun to make headway in elucidating potentially practical strategies to tackle myocardial cell loss as well as the deterioration in cell function, which drives the remodeling process. At the beginning of the 21st century, we are the custodians of an unprecedented wealth of biological and clinical information, which needs to be constructively applied to the goal of recovering the function of the myocardium via reverse remodeling at the cellular level. Novel modalities for use in the drug-refractory patient have emerged based on the replacement of lost cells, gene therapy to modify cellular function and device therapy to resynchronize (cardiac resynchronization therapy, or CRT) and support ventricular function (left ventricular assist device therapy, or LVAD - see Table 1). Recent research advances in this field have been summarized by Koitabashi and Kass [3]. In this article, we explore two emerging targets for specific reverse remodeling-the transverse tubules ( $\mathrm{t}$-tubules) and sarcoplasmic reticulum/ endoplasmic reticulum $\mathrm{Ca}^{2+}$-ATPase (SERCA2a) - and we debate how this emerging molecular knowledge could be used in the future. These are two of many emerging targets including the $\mathrm{Na}^{+} / \mathrm{Ca}^{2+}$ exchanger [4] and the ryanodine receptor (RyR) [5], which have not been discussed in this article.

\section{Myocardial excitation and contractility}

The cardiomyocyte contracts in response to chemical messengers centered around $\mathrm{Ca}^{2+}$, which are tightly regulated in space and time [6]. Malfunctions of this system appear to play a major role in the pathogenesis of $\mathrm{HF}$, and represent a major element of cellular remodeling [7].

\section{Transverse tubules}

The spatial and temporal regulation of the contractile signal is set by ion channels organized around a system 
Table I. The major advances and challenges of emerging therapies for heart failure

\begin{tabular}{|c|c|c|}
\hline & Recent advances & Long-term challenges \\
\hline \multirow[t]{6}{*}{ Cell therapy } & $\begin{array}{l}\text { - Demonstration of marked capacity of neonatal } \\
\text { mammalian heart for regeneration }\end{array}$ & $\begin{array}{l}\text { - Mainly transient clinical improvements with limited } \\
\text { evidence of retention of exogenous cells }\end{array}$ \\
\hline & $\begin{array}{l}\text { Demonstration of residual capacity of adult human } \\
\text { heart for minor regeneration }\end{array}$ & $\begin{array}{l}\text { - Mismatch between improvements in animal models and } \\
\text { those observed in clinical trials }\end{array}$ \\
\hline & $\begin{array}{l}\text { - Continued demonstration of small clinical } \\
\text { improvements in clinical trials }\end{array}$ & $\begin{array}{l}\text { - Continuing debate about correct cell type and mode of } \\
\text { delivery }\end{array}$ \\
\hline & & - Uncertain therapeutic mechanisms \\
\hline & & - Possible arrhythmia risk \\
\hline & & $\begin{array}{l}\text { - Potential need to modulate immune response if non-self } \\
\text { cells used }\end{array}$ \\
\hline \multirow[t]{5}{*}{ Gene therapy } & - Targeted therapy of $\mathrm{Ca}^{2+}$ handling genes shows & - Largely clinically untested \\
\hline & remarkable benefits in animal models & - Long-term effects unknown \\
\hline & $\begin{array}{l}\text { Evidence that multiple levels of the same regulatory } \\
\text { axis can be targeted using gene therapy }\end{array}$ & \\
\hline & $\begin{array}{l}\text { - Potential to harness much of our knowledge of } \\
\text { cellular pathophysiology }\end{array}$ & \\
\hline & $\begin{array}{l}\text { - Some evidence that gene therapy is clinically safe } \\
\text { and has some efficacy }\end{array}$ & \\
\hline \multirow[t]{5}{*}{ Left ventricular assist device } & - Recovery has been demonstrated in multiple patient & - Complications remain serious \\
\hline & populations at a rate of between $5 \%-10 \%$ and up to $73 \%$. & - Requires major operation \\
\hline & $\begin{array}{l}\text { - Left ventricular assist devices appear to induce } \\
\text { reverse remodeling in multiple systems }\end{array}$ & - Debate as to how common cardiac recovery is \\
\hline & - Reverse remodeling is long-lasting & $\begin{array}{l}\text { - Centers may be reluctant to explant devices in fear of } \\
\text { recurrence of heart failure }\end{array}$ \\
\hline & $\begin{array}{l}\text { - Complications are becoming less important } \\
\text { in newer generations }\end{array}$ & $\begin{array}{l}\text { - Mechanical unloading may have deleterious effects such } \\
\text { as atrophy and fibrosis }\end{array}$ \\
\hline \multirow[t]{5}{*}{ Cardiac resynchronization therapy } & - Improves contractility acutely & - Unknown how long-term improvements are \\
\hline & - Reverse remodeling of left ventricular structure & - What is the role in early heart failure without major \\
\hline & - Improved mitochondrial function & dysynchrony? \\
\hline & - Improved subcellular remodeling & \\
\hline & - Safe & \\
\hline
\end{tabular}

of deep membrane invaginations termed t-tubules $[8,9]$. Loss and disorganization of these structures result in aberrant $\mathrm{Ca}^{2+}$ handling and blunted contractility, a subject which we have previously reviewed [8]. Such t-tubule damage appears to be an early event in HF and related to overall contractile dysfunction [10]. The t-tubules are normally responsible for ensuring synchronous $\mathrm{Ca}^{2+}$ activation, and when the t-tubules are lost or their structure is degraded, such synchronicity is lost, leading to the impaired activation of the contractile apparatus. The degree of detubulation has been correlated with ejection fraction in animal models [10]. Detubulation has also been documented in humans, in which HFs secondary to dilated, hypertrophic, or ischemic cardiomyopathy all result in impaired t-tubule structure [11].

Stølen et al. [12] in 2009 first described the reversibility of the t-tubular defects by using a model of diabetic cardiomyopathy. Recovery of the t-tubules was induced by exercise, without improving the glycemic profile, indicating a primary effect on the heart, presumably through the induction of physiological hypertrophy. Subsequently, Sachse et al. [13] showed that cardiac resynchronization therapy in a canine HF model induced recovery in the t-tubules. Xie et al. [14] went on to show that the vasodilator sildenafil was able to improve t-tubule structure in a model of induced pulmonary hypertension-related right HF. T-tubule remodeling was also shown to be prevented by $\beta$-adrenoceptor blockade of the infarcted heart by Chen et al. [15], an important finding in view of the central role of $\beta$-blockade in the management of post-ischemic cardiomyopathy. Administration of SERCA2a gene therapy into postischemic HF animal models [16] improves t-tubule structure, possibly through indirect reverse remodeling. Targeting molecules responsible for regulating t-tubule structure directly, such as junctophilin-2 (JPH2, a protein that anchors the t-tubule and sarcoplasmic reticulum [SR] membranes), achieves similar enhancements of t-tubule structure and also enhances cardiac function [17]. 
In a post-ischemic cardiomyopathy animal model, we showed that the use of a LVAD support (using the heterotopic abdominal heart transplantation technique) [18] was sufficient to enhance t-tubule structure and function. Enhancements of t-tubule and cell surface structure were also documented by using electron microscopy and scanning ion conductance microscopy [18]. These changes were accompanied by the reversal of pathological $\mathrm{Ca}^{2+}$ handling, evidenced by faster, more synchronous $\mathrm{Ca}^{2+}$ transients. Importantly, $\mathrm{SR} \mathrm{Ca}^{2+}$ content was also enhanced. We were able to show that these changes were accompanied by the molecular localization of L-type and RyR channels, providing a possible mechanism.

In a clinical study, we showed that enhanced SR $\mathrm{Ca}^{2+}$ content was a feature of cardiomyocytes in patients who recovered, indicating it might be a deterministic event [19]. We did not examine t-tubule structure in this study but considering the experimental evidence of unloadinginduced t-tubule recovery, we may summarize the present data as showing that mechanical unloading may reverse pathological remodeling in the t-tubules and enhance SR $\mathrm{Ca}^{2+}$ content. Likewise, specific manipulation of SERCA2a via gene therapy induces reverse remodeling of the t-tubules as well as SR $\mathrm{Ca}^{2+}$ content [16]. In addition, genetic manipulation, which rescues JPH2, recovers t-tubule structure and $\mathrm{Ca}^{2+}$ transient amplitude [17]. These data suggest that there are multiple pathways to induce remodeling and that therapies targeting specific pathways as well as classic, non-molecularly targeted therapies may induce reverse remodeling of the same targets (Figure 1).

\section{SERCA2 $a^{+}$}

In the healthy heart, myocyte contractility is dependent on the $\mathrm{Ca}^{2+}$ in- and outflux from the SR. In systole, plasma membrane depolarization leads to an influx of $\mathrm{Ca}^{2+}$ through L-type $\mathrm{Ca}^{2+}$ channels, in turn triggering an efflux of $\mathrm{Ca}^{2+}$ from the SR via RyR type 2 (RyR2) channels. This process is called $\mathrm{Ca}^{2+}$-induced $\mathrm{Ca}^{2+}$ release, in which the released $\mathrm{Ca}^{2+}$ binds to troponin $\mathrm{C}$ and initiates actin-myosin cross-binding, resulting in muscle contraction. During diastole, $\left[\mathrm{Ca}^{2+}\right]_{\text {cytosol }}$ is restored by the resequestration of $\mathrm{Ca}^{2+}$ into SERCA2a in a process called excitation-contraction (EC) coupling [6].

In cardiac failure, the EC coupling process is undermined by reduced intracellular $\mathrm{Ca}^{2+}$ cycling and decreased $\left[\mathrm{Ca}^{2+}\right]_{\mathrm{SR}}$, attributable partly to defects in RyR2 and SERCA2a activity [6]. RyR2 becomes incompetent, "leaking" $\mathrm{Ca}^{2+}$ through a variety of pathways, leading to $\mathrm{Ca}^{2+}$ depletion from the SR and the abnormal depolarization of cardiomyocytes and fatal arrhythmias [20].
SERCA2a expression is decreased and the ability of SERCA2a to allow $\mathrm{Ca}^{2+}$ movement is hampered by the defective phosphorylation and excess dephosphorylation of phospholamban $[6,21]$, leading to increased $\left[\mathrm{Ca}^{2+}\right]_{\text {cytosol }}$ during diastole and reduced $\left[\mathrm{Ca}^{2+}\right]_{\text {cytosol }}$ in systole. A reversion or normalization of this pattern is commonly observed in therapies that reverse cardiac remodeling [3].

Other mechanisms in the activation cascade of SERCA2a have also been identified to contribute to its malfunctioning in cardiac failure, namely the depressed activity of inhibitor 1 (I-1) and excess protein kinase $\mathrm{C}$ activity $(\mathrm{PKC} \alpha)$, resulting in reduced SERCA2a-regulated $\mathrm{Ca}^{2+}$ movement across the SR membrane. Additionally, the post-translational SUMOylation of SERCA2a (a posttranslational modification that has been shown to be necessary for stabilizing and preserving the activity of SERCA2a) has been shown to be reduced in failing hearts [22]. All these sites involved in the formation and regulation of SERCA2a activity offer potential targets for therapy in cardiac failure.

Gene therapy directly targeting SERCA2a has been successfully tried in phase 1 and 2 trials with a threeyear follow-up in the Calcium Upregulation by Percutaneous Administration of Gene Therapy in Cardiac Disease (CUPID 1) study [23]. This is the first clinical gene therapy trial in humans that uses an adenoassociated virus (AAV1) vector to carry SERCA2a to the coronary arteries in patients with advanced cardiac failure. Recipients have shown decreased rates of myocardial infarction, worsening HF, HF-associated hospitalization, placement of VADs, heart transplantation, and death in comparison with placebo [23]. The study is now entering a phase 3 trial. A second trial (NCT00534703), the SERCA gene therapy trial, to determine the safety and feasibility of giving an AAV-vector expressing SERCA2a to HF patients is currently being set up to run in the UK and USA by Imperial College London.

There is a concern, however, that simply correcting the $\mathrm{Ca}^{2+}$ balance in the cardiac cycle in a damaged heart could have detrimental effects on the damaged cardiomyocytes [24]. In fact, Louch et al. [25] found that normalizing global cardiomyocyte $\mathrm{Ca}^{2+}$ homeostasis may not be protective against hypertrophy and the development of HF. Yet gene therapy directly targeting SERCA2a appears to set in train a wide range of cellular reverse remodeling events, including the reversal of the t-tubule loss observed in HF [26]. Importantly, LVAD therapy has also been shown to enhance SERCA expression (in one study, enhanced SR $\mathrm{Ca}^{2+}$ stores were required for clinical recovery [19]), which demonstrates how the interplay of 
Figure I. Combinatorial Left Ventricular Assist Device and targeted gene therapy for the modern management of heart failure

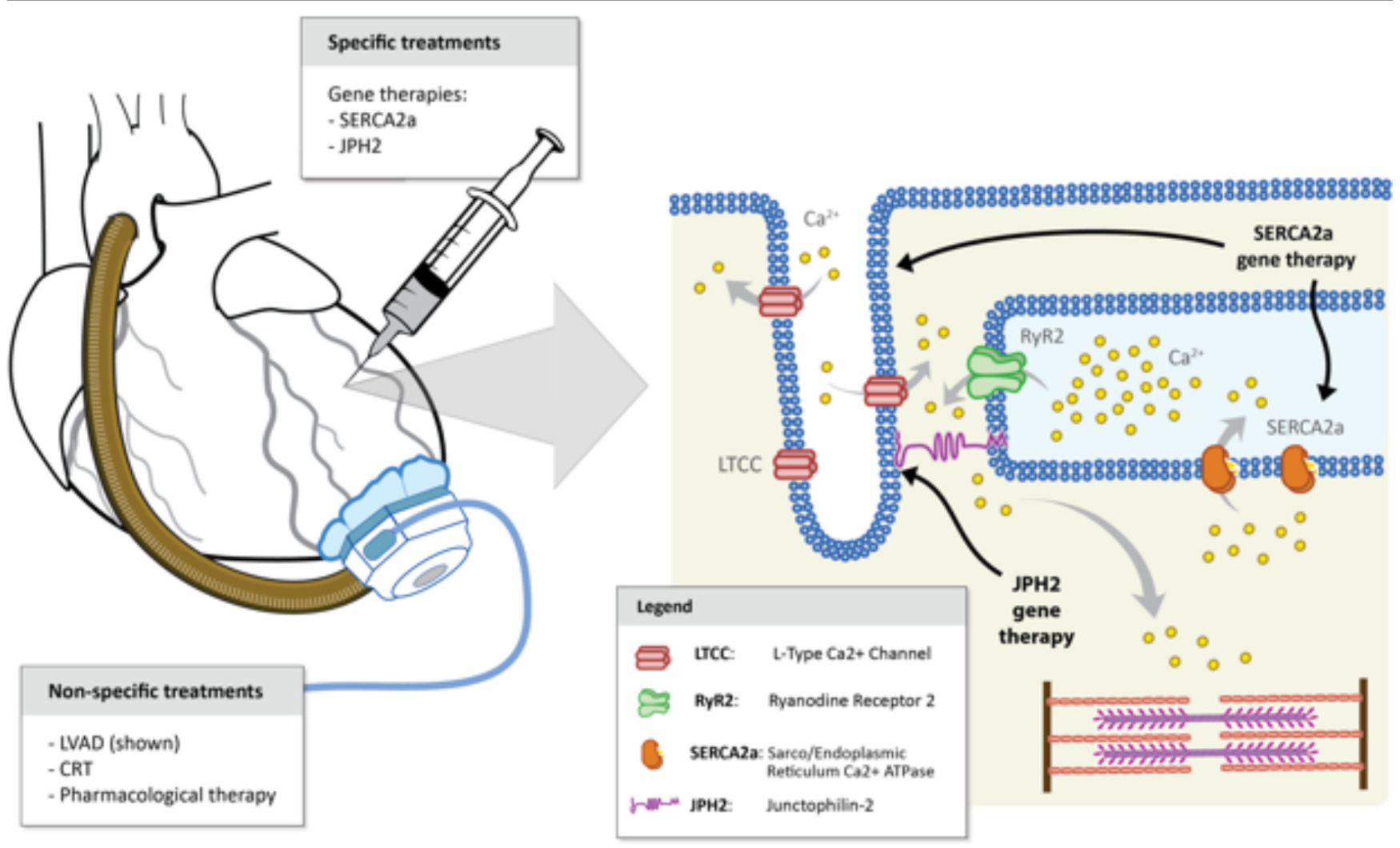

Left Ventricular Assist Device (LVAD) therapy provides an effective treatment modality in its own right and as a platform to maximise the efficacy of emerging treatment modalities, including gene and cell therapy. Abbreviations: CRT, cardiac resynchronization therapy; SERCA2a, sarcoplasmic reticulum/endoplasmic reticulum $\mathrm{Ca}^{2+}$-ATPase.

different treatment modalities may be complementary. Recent evidence also shows that targeting the posttranslational modification of the genetic axis regulating SERCA2a function can yield similarly positive results (for example, by modulating SUMOylation) [22].

\section{The future}

Taken together, the current literature supports the notion that the reversal of t-tubule dysfunction may be achieved through different pathways. These include strategies that induce widespread reverse remodeling in multiple targets (for example, beta-blockade and LVAD therapy). However, the work of van Oort et al. [17] has shown that it is possible to target directly the t-tubule system by altering JPH2 expression, with considerable effects on overall cardiac performance. A similar pattern has been observed for SERCA2a. For example, we showed that LVAD therapy induces cardiac recovery partly because it enhances SERCA2a [19]. Knowledge of the mechanisms of both progression and regression of HF, and also of tools to modify these mechanisms, is growing rapidly. The question we will shortly face is how best to apply this knowledge. In the future, will patients receive a regimen of gene therapy aimed at reversing dysfunction in multiple molecular pathways (for example, JPH2 and SERCA2a)? Will this usurp the classic pharmacological therapies that target multiple mechanisms (Figure 1)? It is imperative to better define the pathophysiology of human HF, enabling the selective targeting of molecular pathways with potential clinical benefit. A reclassification of HF along molecular lines could unlock the full potential of targeted molecular therapies.

\section{Conclusions}

The future therapy of HF will be based on the combined use of multiple modalities, perhaps at different stages of the disease and in different patient populations. The present generation of academic cardiovascular scientists and clinicians have many choices to make, which will determine the speed and success of reaching this goal. 
We believe that it is necessary to repeatedly return to the essential physiology that inspired many of these therapies in order to properly tailor their use. We shall need to choose between intensive efforts to restore and repair cardiac function or increasing replacement of the biological heart with devices and exogenous tissues. The best results will be obtained when we are able to precisely define the mechanisms driving the benefits of LVADs, CRT, and cell and gene therapy and use this to develop strategies to harness the adaptability of the native heart.

\section{Abbreviations}

$\mathrm{AAV}$, adeno-associated virus; ACEi, angiotensin-converting enzyme inhibitor; CRT, cardiac resynchronization therapy; EC, excitation-contraction; HF, heart failure; JPH2, junctophilin-2; LVAD, left ventricular assist device; RyR, ryanodine receptor; SR, sarcoplasmic reticulum; SERCA2a, sarcoplasmic reticulum/endoplasmic reticulum $\mathrm{Ca}^{2+}$-ATPase; $\mathrm{t}$-tubule, transverse tubule.

\section{Disclosures}

The authors declare that they have no disclosures.

\section{References}

I. Pfeffer MA, Braunwald E: Ventricular remodeling after myocardial infarction. Experimental observations and clinical implications. Circulation 1990, 81:1161-72.

2. Belardinelli R, Georgiou D, Scocco V, Barstow TJ, Purcaro A: Low intensity exercise training in patients with chronic heart failure. J Am Coll Cardiol 1995, 26:975-82.

3. Koitabashi N, Kass DA: Reverse remodeling in heart failuremechanisms and therapeutic opportunities. Nat Rev Cardiol 2012, 9:147-57.

4. Sipido KR, Volders PGA, Vos MA, Verdonck F: Altered $\mathbf{N a / C a}$ exchange activity in cardiac hypertrophy and heart failure: a new target for therapy? Cardiovasc Res 2002, 53:782-805.

\section{FlOOOPrime}

\section{RECOMMENDED}

5. Lehnart SE: Novel targets for treating heart and muscle disease: stabilizing ryanodine receptors and preventing intracellular calcium leak. Curr Opin Pharmacol 2007, 7:225-32.

\section{FlOOOPrime}

\section{RECOMMENDED}

6. Bers DM: Cardiac excitation-contraction coupling. Nature 2002, 415:198-205.

7. Bers DM: Altered cardiac myocyte $\mathbf{C a}$ regulation in heart failure. Physiology (Bethesda) 2006, 2 I:380-7.

\section{FlOOOPrime}

\section{RECOMMENDED}

8. Ibrahim M, Gorelik J, Yacoub MH, Terracciano CM: The structure and function of cardiac t-tubules in health and disease. Proc Biol Sci 20II, 278:27|4-23.

9. Orchard C, Brette F: t-Tubules and sarcoplasmic reticulum function in cardiac ventricular myocytes. Cardiovasc Res 2008 , 77:237-44.

FlOOOPrime
RECOMMENDED

10. Wei S, Guo A, Chen B, Kutschke W, Xie Y, Zimmerman K, Weiss RM, Anderson ME, Cheng H, Song L: T-tubule remodeling during transition from hypertrophy to heart failure. Circ Res 2010, I07:520-3I.

\section{FlOOOPrime
RECOMMENDED}

II. Lyon AR, MacLeod KT, Zhang Y, Garcia E, Kanda GK, Lab MJ, Korchev YE, Harding SE, Gorelik J: Loss of T-tubules and other changes to surface topography in ventricular myocytes from failing human and rat heart. Proc Natl Acad Sci USA 2009, I 06:6854-9.

\section{FlOOOPrime
RECOMMENDED}

12. Stølen TO, Høydal MA, Kemi OJ, Catalucci D, Ceci M, Aasum E, Larsen T, Rolim N, Condorelli G, Smith GL, Wisløff U: Interval training normalizes cardiomyocyte function, diastolic $\mathrm{Ca2+}$ control, and SR Ca2+ release synchronicity in a mouse model of diabetic cardiomyopathy. Circ Res 2009, I 05:527-36.

\section{FlOOOPrime
RECOMMENDED}

13. Sachse FB, Torres NS, Savio-Galimberti E, Aiba T, Kass DA, Tomaselli GF, Bridge $\mathrm{JH}$ : Subcellular structures and function of myocytes impaired during heart failure are restored by cardiac resynchronization therapy. Circ Res 2012, I 1 0:588-97.

\section{FlOOOPrime} RECOMMENDED

14. Xie Y, Chen B, Sanders P, Guo A, Li Y, Zimmerman K, Wang L, Weiss RM, Grumbach IM, Anderson ME, Song L: Sildenafil prevents and reverses transverse-tubule remodeling and $\mathrm{Ca}(2+)$ handling dysfunction in right ventricle failure induced by pulmonary artery hypertension. Hypertension 2012, 59:355-62.

15. Chen B, Li Y, Jiang S, Xie Y, Guo A, Kutschke W, Zimmerman K, Weiss RM, Miller FJ, Anderson ME, Song L: $\beta$-Adrenergic receptor antagonists ameliorate myocyte T-tubule remodeling following myocardial infarction. FASEB J 2012, 26:2531-7.

\section{FlOOOPrime
RECOMMENDED}

16. Lyon AR, Nikolaev VO, Miragoli M, Sikkel MB, Paur H, Benard L, Hulot J, Kohlbrenner E, Hajjar RJ, Peters NS, Korchev YE, MacLeod KT, Harding SE, Gorelik J: Plasticity of surface structures and $\beta(2)$-adrenergic receptor localization in failing ventricular cardiomyocytes during recovery from heart failure. Circ Heart Fail 2012, 5:357-65.

\section{FlOOOPrime}

RECOMMENDED

17. van Oort RJ, Garbino A, Wang W, Dixit SS, Landstrom AP, Gaur N, Almeida AC de, Skapura DG, Rudy Y, Burns AR, Ackerman MJ, Wehrens XHT: Disrupted junctional membrane complexes and hyperactive ryanodine receptors after acute junctophilin knockdown in mice. Circulation 201 I, I 23:979-88.

\section{FlOOOPrime}

\section{RECOMMENDED}

18. Ibrahim M, Navaratnarajah M, Siedlecka U, Rao C, Dias P, Moshkov AV, Gorelik J, Yacoub MH, Terracciano CM: Mechanical unloading reverses transverse tubule remodelling and normalizes local $\mathrm{Ca}(2+)$-induced $\mathrm{Ca}(2+)$ release in a rodent model of heart failure. Eur J Heart Fail 2012, I4:57I-80.

19. Terracciano CMN, Hardy J, Birks EJ, Khaghani A, Banner NR, Yacoub $\mathrm{MH}$ : Clinical recovery from end-stage heart failure using left-ventricular assist device and pharmacological therapy correlates with increased sarcoplasmic reticulum calcium content but not with regression of cellular hypertrophy. Circulation 2004, 109:2263-5. 
20. Park W], Oh JG: SERCA2a: a prime target for modulation of cardiac contractility during heart failure. BMB Rep 20I3, 46:237-43.

21. Gwathmey JK, Copelas L, MacKinnon R, Schoen FJ, Feldman MD, Grossman W, Morgan JP: Abnormal intracellular calcium handling in myocardium from patients with end-stage heart failure. Circ Res 1987, 61:70-6.

\section{FIOOOPrime}

22. Kho C, Lee A, Jeong D, Oh JG, Chaanine AH, Kizana E, Park WJ, Hajiar RJ: SUMOI-dependent modulation of SERCA2a in heart failure. Nature 20II, 477:60I-5.

\section{FlOOOPrime}

23. Zsebo K, Yaroshinsky A, Rudy J], Wagner K, Greenberg B, Jessup M, Hajjar RJ: Long-Term Effects of AAVI/SERCA2a Gene Transfer in Patients With Severe Heart Failure: Analysis of Recurrent Cardiovascular Events and Mortality. Circ Res 20I4, I | 4:10|-8.
24. Zouein FA, Booz GW: AAV-mediated gene therapy for heart failure: enhancing contractility and calcium handling. Fl000Prime Rep 2013, 5(27)

\section{FIOOOPrime}

\section{RECOMMENDED}

25. Louch WE, Vangheluwe P, Bito V, Raeymaekers L, Wuytack F, Sipido KR: Phospholamban ablation in hearts expressing the high affinity SERCA2b isoform normalizes global $\mathrm{Ca}^{2+}$ homeostasis but not $\mathrm{Ca}^{2+}$-dependent hypertrophic signaling. Am J Physiol Heart Circ Physiol 20 12, 302:H2574-82.

\section{FlOOOPrime}

RECOMMENDED

26. Lyon $A R$, Bannister ML, Collins $T$, Pearce $E$, Sepehripour $A H$, Dubb SS, Garcia E, O'Gara P, Liang L, Kohlbrenner E, Hajjar RJ, Peters NS, Poole-Wilson PA, MacLeod KT, Harding SE: SERCA2a gene transfer decreases sarcoplasmic reticulum calcium leak and reduces ventricular arrhythmias in a model of chronic heart failure. Circ Arrhythm Electrophysiol 20II, 4:362-72.

\section{FlOOOPrime}

